\title{
FIRST RECORD OF EUCLINOSTOMUM HETEROSTOMUM FROM THE NATURALLY-INFECTED HERON "ARDEOLA RALLOIDES" IN EGYPT: A LIGHT \& SCANNING ELECTRON MICROSCOPY STUDY
}

\author{
Reda M. Mansour* \\ Zoology and Entomology Department, Faculty of Science, Helwan University, Cairo, Egypt
}

\begin{abstract}
Article History:
Received: 18 October 2019

Revised: 2 November 2019

Accepted: 4 November 2019

Published Online:

9 November 2019

Keywords:

Euclinostomum heterostomum

Natural infection

Scanning electron microscopy

Squacco herons

Surface topography

*Correspondence:

Reda Mansour

Zoology and Entomology

Department, Faculty of Science

Helwan University, Cairo

Egypt

E-mail:

reda_mansour@science.helwan. edu.eg
\end{abstract}

\begin{abstract}
Four adult specimens of clinostomatid parasites were recovered from the buccal cavity and oesophagus of a naturally-infected male squacco heron, Ardeola ralloides (Aves: Ardeidae), collected in July 2019 from Giza Province, Egypt. The rate of natural infection was recorded as $10 \%(1 / 10)$. The parasite has the typical body plan organization of Euclinostomum heterostomum Rudolphi, 1809 (Digenea: Clinostomatidae) with minor differences in certain organs measurements. The body dimensions measure 5.57-6.71 $\times 2.29-2.97 \mathrm{~mm}$ (length $\times$ maximum body width). The oral sucker locates in the centre of the oral collar and measures $0.36-0.44 \times 0.53-0.64 \mathrm{~mm}$, while the ventral sucker locates in the anterior third of body and measures $0.65-1.10$ $\times 0.63-1.27 \mathrm{~mm}$. The right intestinal caecum gives rise to 11-14 diverticula, while the left intestinal caecum gives rise to 12-15 diverticula. The testes are tandem and lie in the posterior third of the body. The anterior testis is U-shaped and measures $0.61-0.70 \times 0.85-1.26 \mathrm{~mm}$, while the posterior testis is tripartite and measures $0.60-0.67 \times 0.66-0.69 \mathrm{~mm}$. The ovary is intertesticular, dextral to median body plan, and measures $0.22-0.25 \times 0.33-0.37 \mathrm{~mm}$. The uterus is pretesticular, intercaecal, filled with hundreds of eggs, and measures 1.54-2.13 $\times 0.59-1.32 \mathrm{~mm}$. The uterine eggs are ellipsoidal; each measures $0.11-0.12 \times 0.06-0.08 \mathrm{~mm}$. The excretory pore is subterminal, intercaecal, and measures 0.12-0.14 $\times 0.12-0.14 \mathrm{~mm}$. In addition, the surface topographies of the ventral and the dorsal surfaces of body were described.
\end{abstract}

\section{INTRODUCTION}

Euclinostomum Travassos, 1928 is a speciespoor genus belonging to subfamily Euclinostominae, family Clinostomatidae within the digenetic trematodes ${ }^{[1-3]}$. Family Clinostomatidae contains four subfamilies: Nephrocephalinae, Euclinostominae, Clino- stominae, and Ithyoclinostominae. The adults of Nephrocephalinae are found in the buccal cavity and oesophagus of reptiles, while the adults of Euclinostominae, Clinostominae and Ithyoclinostominae are found in the buccal cavity and oesophagus of birds, and occasionally in mammals ${ }^{[1,3]}$. 
Out of subfamilies infecting birds, adults of Euclinostominae possess caeca with numerous lateral branches and diverticula, while adults of other two subfamilies possess simple caeca without lateral branches and diverticula ${ }^{[1,3]}$. Concerning the validity of Euclinostomum species, four species are considered as valid. Fischthal and Kuntz ${ }^{[4]}$ recognized adults of previously described four Euclinostomum spp., E. vanderkuypi, E. heterostomum, E. dollfusi, E. bhagavantami, as valid. However, Ukoli ${ }^{[2]}$ synonymized many species to E. heterostomum on the basis of location of the metacercaria and adults within their hosts, morphological variations of E. heterostomum, and other considerations. In addition, $\mathrm{Ukoli}^{[2]}$ regarded only two previously recognized species "E. heterostomum and E. multicaecum" as valid. Moreover, Jhansilakshmibai and Madhavi ${ }^{[5]}$ considered two more species, E. minutus from Pakistan ${ }^{[6]}$ and E. ardeolae from Egypt $^{[7]}$, as valid species.

Euclinostomum species have a three-host life cycle. The adult inhabits the oral cavity and oesophagus of piscivorous birds (definitive host), the metacercariae occur in the muscles, gill chambers, and kidneys of fish as $2^{\text {nd }}$ intermediate host, and the redia is carried by snails as $1^{\text {st }}$ intermediate host $^{[7,8]}$. Ukoli ${ }^{[2]}$ recovered metacercaria of E. heterostomum from body wall in the kidney region of Tilapia zilli and T. heudeloti, and obtained adults from experimentally infected African darter "Anhinga rufa rufa" and long-tailed shag "Phalacrocorax africanus africanus", but no cattle egrets. In addition, El-Naffar and $\mathrm{Khalifa}^{[7]}$ recorded metacercaria of $E$. ardeolae from kidneys of naturallyinfected Oreochromis (Syn. Tilapia) nilotica, and adults from experimentally infected buff-backed heron "Ardeola ibis ibis". Moreover, Jhansilakshmibai and Madhavi ${ }^{[5]}$ recorded the presence of E. heterostomum metacercaria in the kidneys and liver of Channa punctatus, and muscles of C. orientalis. In addition, they obtained the $E$. heterostomum adults from the experimentally infected pond heron "Ardeola grayii" and cattle egret "Bubulcus

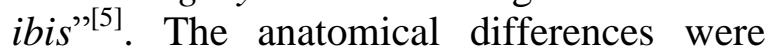
recorded between metacercaria, juvenile, and gravid adults of E. ardeolae. Juvenile adults have tegument totally covered by minute spines, slight sacculation of anterior part of intestinal caeca, slightly bigger gonads, and ova begin to appear in the loops of the uterus, while gravid adults have a dilated coiled uterus totally filled with ova ${ }^{[7]}$.

Squacco heron "Ardeola ralloides Scopoli, 1769" is a small heron feeding on fish, frogs, and insects. It is recorded as migratory and resident species in Egypt $^{[9,10]}$. The present study aimed to investigate the morphological features and surface topography of adult worms of E. heterostomum from naturally-infected Ardeola ralloides in Egypt using light and scanning electron microscopy.

\section{MATERIAL AND METHODS Experimental animals}

Four males and six females squacco herons “Ardeola ralloides Scopoli, 1769" were captured from March to July 2019 from Abu-Rawash (Giza Province, Egypt) and examined for the presence of helminths.

\section{Light microscopy}

Following dissection, trematodes were fixed and held in FAA solution (10\% formalin, $85 \%$ alcohol, and 5\% acetic acid) for 24 hours. Then, specimens washed several times in $70 \%$ ethanol, stained overnight in acetocarmine. Afterwards, specimens were destained in weak acid-alcohol until colour differentiation, dehydrated in ascending series of ethanol, cleared in xylene and finally mounted on glass slides using Canada balsam. Photomicrographs of stained whole mounted specimens were studied and photographed using a Zeiss research photomicroscope (Carl Zeiss AG, Oberkochen, Germany).

\section{Scanning electron microscopy}

Specimens were fixed in $2.5 \%$ buffered glutaraldehyde, washed in cacodylate buffer, 
dehydrated in ascending series of ethanol with agitation using automatic tissue processor (Leica Microsystems Pty Ltd, Macquarie Park, Austria). Afterwards, specimens were dried using $\mathrm{CO}_{2}$ critical point drier (Model: Audosamdri-815; Tousimis, Rockville, MD, USA), coated by gold sputter coater (SPI-Module), and finally examined/photographed using scanning electron microscopy (Model: JSM5500 LV; JEOL Ltd, Tokyo, Japan) at the Regional Centre of Mycology and Biotechnology, Cairo, Egypt. Identification of parasites was done following the standard keys ${ }^{[1,3]}$. All measurements are presented as the range, expressed as length $(\mathrm{L}) \times[$ maximum body width $(\mathrm{MW})$ or width (W)], and followed by the mean in parentheses.

\section{RESULTS}

\section{Rate of natural infection}

Out of ten squacco herons "Ardeola ralloides", only one male host (10\%) collected in July 2019 was found to be naturally-infected with the adults of the present Euclinostomum species. The infection was detected in the buccal cavity and oesophagus, and four mature specimens were obtained, two attached to the interior of lower beak and two attached to the tip of trachea.

\section{Description}

Whole worm was schematically drawn (Figure 1), and measurements were based on mature adults recovered from the buccal cavity and oesophagus (Figure 2a). The body is flattened, truncate at anterior end, rounded at posterior end (Figures $2 \mathrm{a}, \mathrm{b}$ and $3 \mathrm{a}$ ), and measures 5.57-6.71 (5.95) $\times 2.29-2.97(2.56) \mathrm{mm}(\mathrm{L} \times \mathrm{MW})$. The MW occurs at first testicular level (Figure 2b) with $\mathrm{MW} / \mathrm{L}$ measuring 41.0-44.3 (43), while L/MW measures 2.26-2.44 (2.33). Tegumental spines are totally absent. A constriction was noticed at the middle level of the ventral sucker (Figure 2b). Anterior extremity with distinct oral collarlike fold typical of the genus (Figures 2c, $\mathrm{d}$ and 3b) surrounds the oral sucker and measures $0.65-0.83(0.74) \times 0.96-0.99$ (0.97) $\mathrm{mm}$ with oral collar $\mathrm{L} / \mathrm{W}$ ratio measuring 0.66-0.86 (0.76). The thickness of the oral collar rim measures $0.12-0.17$ $(0.15) \mathrm{mm}$. Oral sucker is subterminal, oval in shape, and locates at the centre of the oral collar and measures $0.36-0.44(0.40) \times 0.53$ $0.64(0.58) \mathrm{mm}$ with mean of $\mathrm{L} / \mathrm{W}$ ratio measuring 0.69 . The thickness of the oral sucker rim measures 0.17-0.21 (0.18) $\mathrm{mm}$.

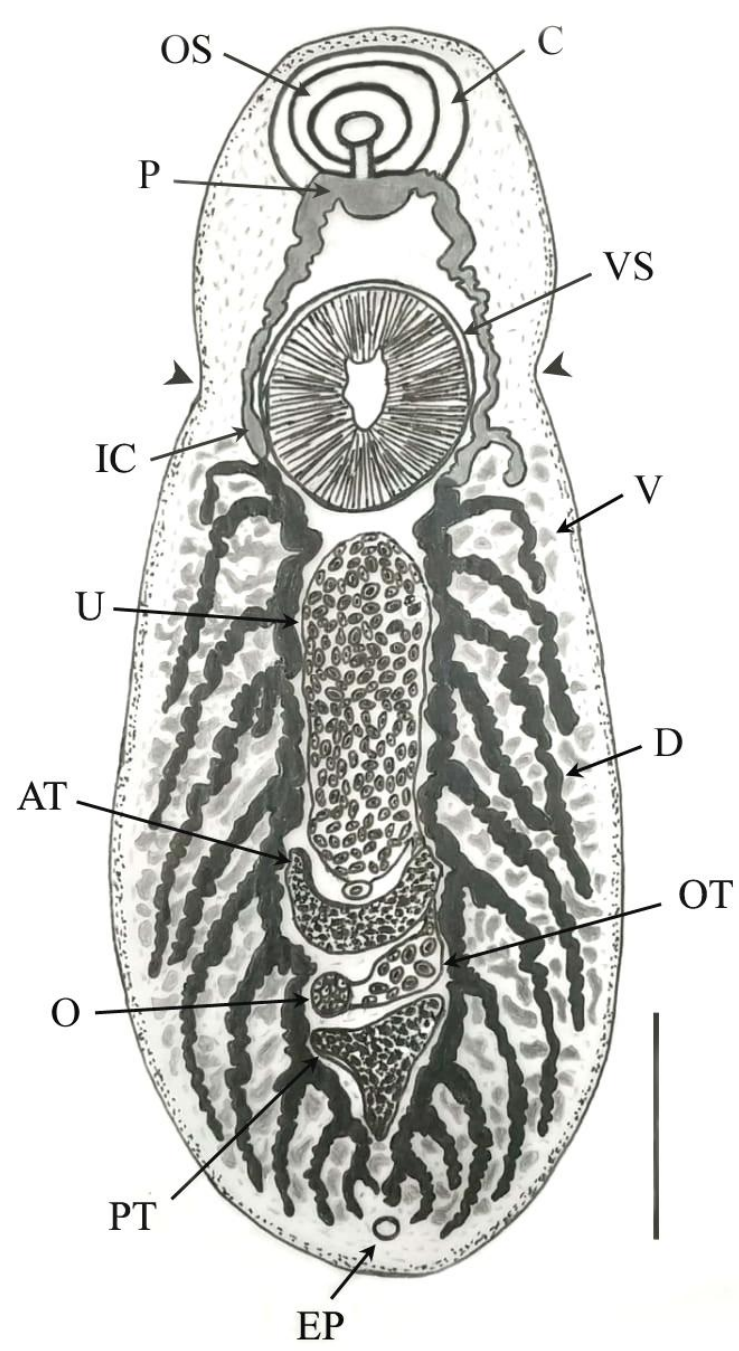

Figure 1: Diagrammatic of the present Euclinostomum sp. showing a constriction at acetabular level. AT: anterior testis, C: collar, D: diverticula of intestinal caecum, EP: excretory pore, IC: intestinal caecum, O: ovary, OS: oral sucker, OT: oötype, $\mathrm{P}$ : pharynx, PT: posterior testis, U: uterus, V: vitelline, VS: ventral sucker. Scale bar $=1 \mathrm{~mm}$. 

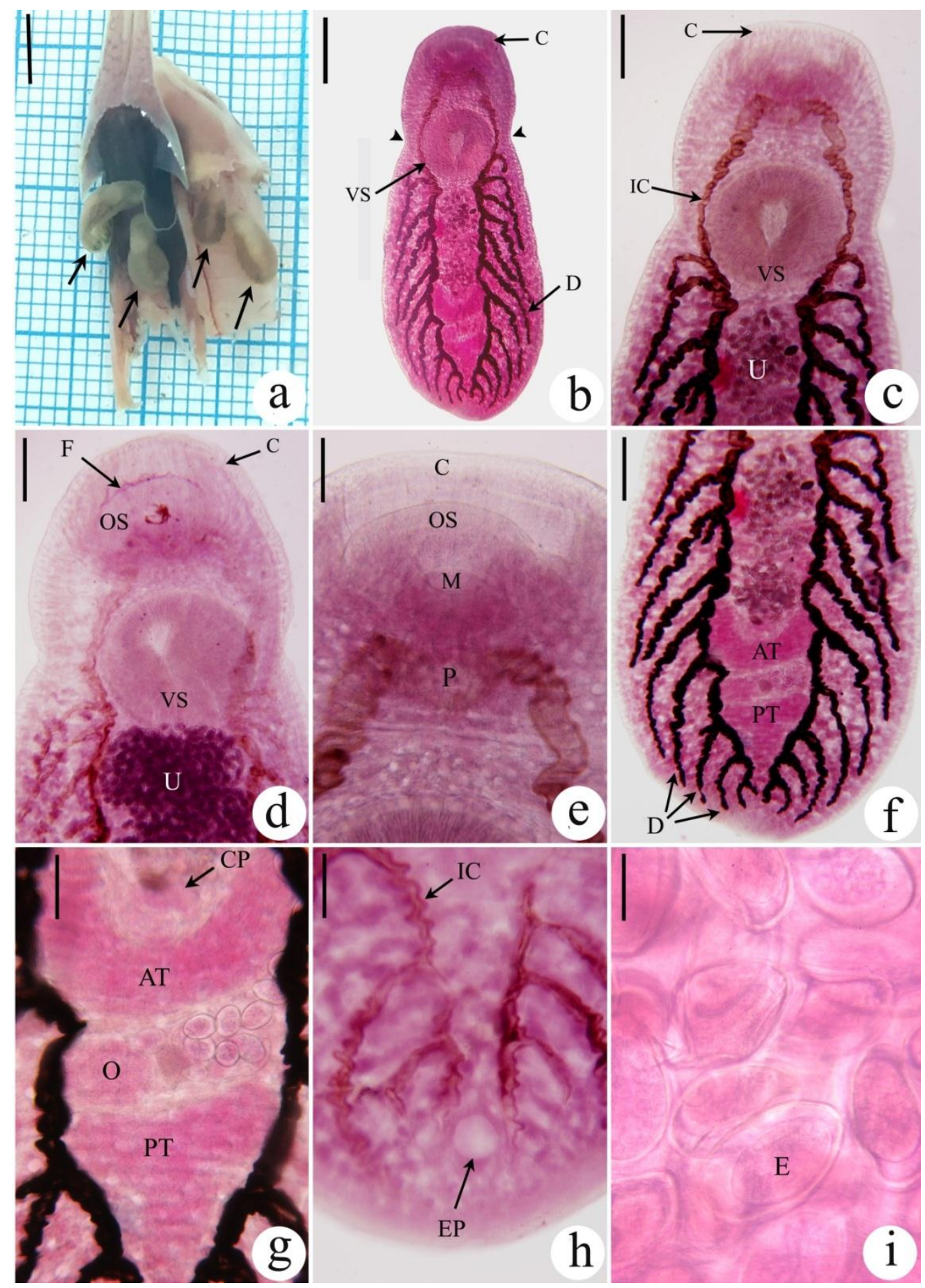

Figure 2: Photomicrographs of the present Euclinostomum sp.: (a) four whole worms (arrows), two attached to interior of lower beak and two attached to tip of trachea; (b) carmine-stained specimen showing a constriction (arrow heads) at acetabular level; (c, d) body regions from anterior extremity to anterior part of uterus. Fold-like structure found dorsal to the oral sucker (d); (e) oral collar surrounding oral sucker; (f) body region from below of acetabulum to posterior extremity of body; (g) body region from cirrus pouch to posterior testes; (h) hind part of body showing the excretory pore; (i) uterine eggs. AT: anterior testis, C: collar, CP: cirrus pouch, D: diverticula of intestinal caecum, E: egg, F: fold, EP: excretory pore, IC: intestinal caecum, M: mouth, O: ovary, OS: oral sucker, P: pharynx, PT: posterior testis, U: uterus, VS: ventral sucker. Scale bar $=5 \mathrm{~mm}$ (a), $2 \mathrm{~mm}$ (b), $0.5 \mathrm{~mm}$ (c, d, f), $0.2 \mathrm{~mm}(\mathbf{e}, \mathbf{g}, \mathbf{h}), 50 \mu \mathrm{m}$ (i). 
Oval mouth opening lies in the centre of the oral sucker (Figures 2e and $3 b$ ) and measures $0.09-0.12(0.11) \times 0.16-0.21$ (0.19) $\mathrm{mm}$. Small fold-like structure is noticed in the area between dorsal rims of oral sucker and oral collar (Figures $2 \mathrm{~d}$ and 3c). The ventral sucker is well-developed, muscular, sub-spherical to ovoid shape, and is located in the anterior third of the body measuring $0.65-1.10(0.94) \times 0.63-1.27$ (0.97) $\mathrm{mm}$ with L/W ratio of $0.87-1.04$ (0.96). The mean ratio of oral sucker to ventral sucker length is $1: 2.34$, while that of width is $1: 1.67$. The thickness of the ventral sucker rim measures $0.22-0.37(0.31) \mathrm{mm}$. At ultrastructure level (Figure 3d); the outer edge of ventral sucker is thin and elevated than body surface level, while the inner edge is thick and continuous with body surface level. The distance between the posterior margin of oral sucker and the anterior margin of ventral sucker is relatively short measuring $0.38-0.39(0.382) \mathrm{mm}$. The forebody is relatively short (Figures 2c, d), measures 1.06-1.24 (1.13) $\mathrm{mm}$ and constitutes $18.5-19.6 \%(19 \%)$ in relation to the whole body length. Hind-body is long, measures 3.45-4.38 (3.87) $\mathrm{mm}$, and represents $61.8-67.8 \%(65 \%)$ to the whole body length.

The digestive system is incomplete (Figures 2e, f) and consists of mouth, short pharynx, and two intestinal caeca extend laterally beneath oral sucker to posterior margin of body. The pharynx is swollen into a bulb-like structure at its base and measures $0.21-0.25(0.23) \times 0.17-0.22(0.20) \mathrm{mm}$. The width of the intestinal caeca measures 0.07 $0.14(0.11) \mathrm{mm}$. The intestinal diverticula begin from the level of lower third of acetabulum and extend only toward outer side of the intestinal caeca. The right intestinal caecum gives rise to 11-14 diverticula, while the left intestinal caecum gives rise to $12-15$ diverticula. The reproductive system comprises two testes and one ovary. The testes are tandem (Figure 2g), and locate in upper region of the posterior third of body. The anterior testis is large, crescent or U-shaped and measures
$0.61-0.70(0.66) \times 0.85-1.26(1.06) \mathrm{mm}$ with $\mathrm{L} / \mathrm{W}$ ratio of $0.56-0.71(0.62)$. The posterior testis is smaller, tripartite, and measures 0.60-0.67 (0.63) × 0.66-0.69 (0.67) mm with $\mathrm{L} / \mathrm{W}$ ratio of 0.87-1.01 (0.94). The distance between the two testes measures $0.32-0.60$ $(0.46) \mathrm{mm}$ with ratio of $0.06-0.09 \%$ $(0.08 \%)$ to the whole body length. Posttesticular space is relatively short, measures 0.60-0.97 (0.79) $\mathrm{mm}$, and represents 10.7$14.5 \%(13.2 \%)$ to the whole body length.

The ovary is small (Figure $2 \mathrm{~g}$ ), intertesticular, dextral to the median body plan, ovoid in shape, and measures 0.22-0.25 $(0.24) \times 0.33-0.37(0.35) \mathrm{mm}$ with mean of $\mathrm{L} / \mathrm{W}$ ratio measuring 0.68 . The oötype is small, oval to elongate-oval, sinistral to the ovary, median to slightly sinistral to the whole median body plan, and measures $0.21-0.24(0.23) \times 0.33-0.39(0.36) \mathrm{mm}$. The uterine sac is filled with hundreds of eggs, intercaecal, occupies from lower margin of the ventral sucker to anterior margin of the anterior testis, and measures 1.54-2.13 (1.84) $\times 0.59-1.32(0.96) \mathrm{mm}$. The uterine field is relatively long and represents $27.6-31.8 \%$ $(30.8 \%)$ to the whole body length. The vitelline fields are extracaecal, restrict to the lateral margins of the body, begin just posterior to the ventral sucker, and extend to the posterior extremity of body. Vitelline gland follicles are dispersed between the intestinal diverticula. The cirrus pouch is oval, median or slightly dextral, and measures $0.22-0.27 \quad(0.24) \times 0.29-0.35$ (0.32) $\mathrm{mm}$. The gonopore (Figure $3 \mathrm{e}$ ) is elongate-oval in shape, pre-testicular, locates in the concavity of the anterior testis at the end of the middle third of the body, and measures 0.053-0.055 $(0.054) \times 0.090-0.092$ $(0.091) \mathrm{mm}$. The excretory pore (Figure $2 \mathrm{~h}$ ) is subterminal, median, intercaecal, spherical in shape, and measures 0.12-0.14 (0.13) $\times 0.12-0.14(0.13) \mathrm{mm}$. The uterine eggs are ellipsoidal; locate within the uterine sac, uterine duct, and oötype region. Each egg is surrounded by a double walled shell (Figure 2i) and measures 0.11-0.12 (0.112) $\times 0.06-0.08(0.07) \mathrm{mm}$ with $\mathrm{L} / \mathrm{W}$ ratio of $1.38-1.78$ (1.53). 

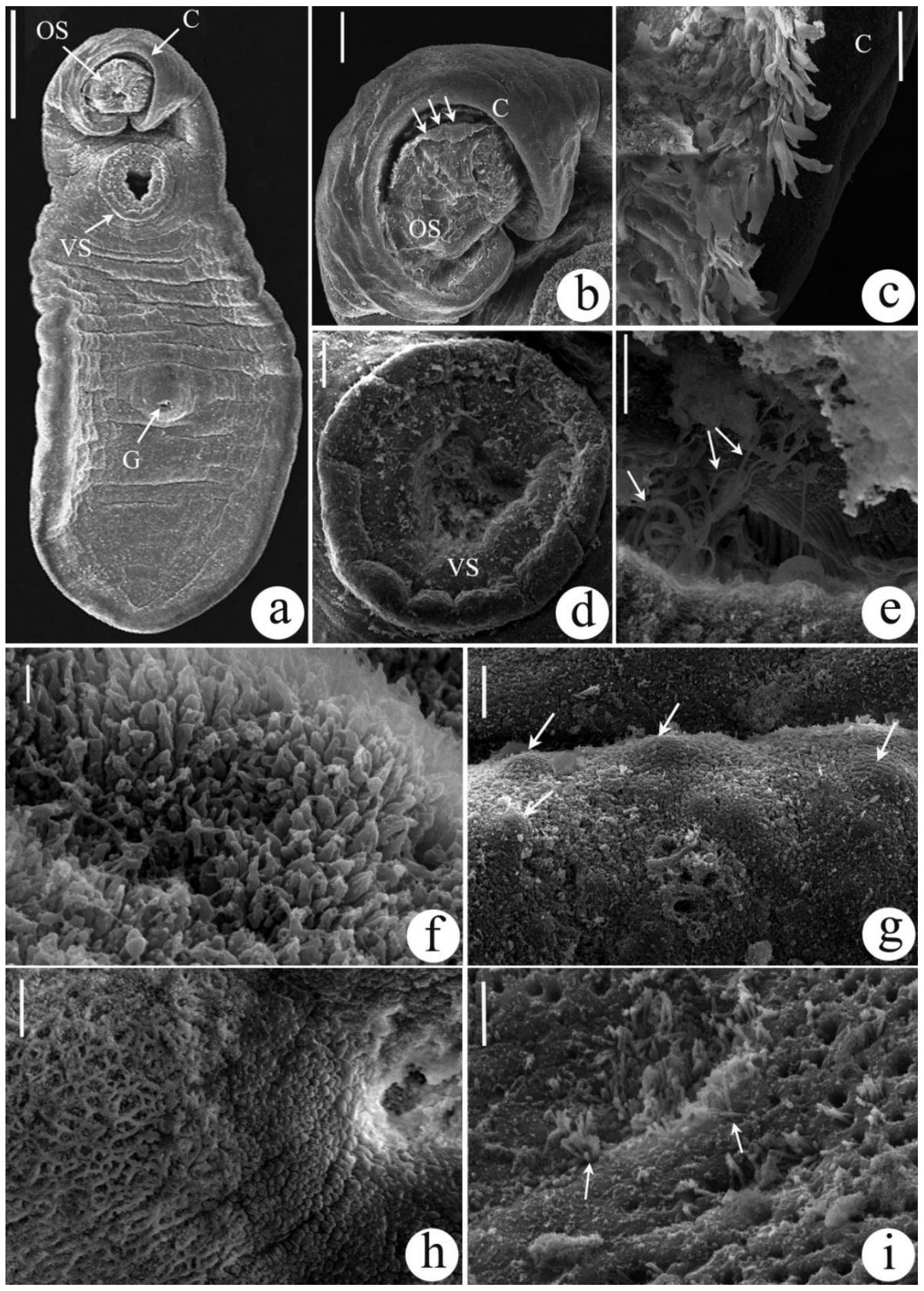

Figure 3: Scanning electron micrographs of the present Euclinostomum sp.: (a) whole worm; (b) collar surrounding oral sucker with fold-like structures (arrows) dorsal to oral sucker; (c) fold-like structures beneath collar and dorsal to oral sucker; (d) ventral sucker; (e) interior of gonopore with spermatozoa-like structures (arrows); (f-i) different tegumental topographies of worm; (f) body surface of lower ventral side of collar; (g) body surface of area below ventral sucker showing very little protrusions (arrows); (h) dorsal body surface of hind end of the body; (i) dorsal area of oral collar with tegumental pits from some of which hairlike structures are emerged (arrows). C: collar, G: gonopore, OS: oral sucker, VS: ventral sucker. Scale bar = $1 \mathrm{~mm}$ (a), $0.2 \mathrm{~mm}$ (b), $50 \mu \mathrm{m}$ (c), $100 \mu \mathrm{m}$ (d), $10 \mu \mathrm{m}$ (e, g, h), $1.0 \mu \mathrm{m}$ (f), $5 \mu \mathrm{m}(\mathbf{i})$. 
At ultrastructure level of the ventral surface, body tegument is formed of fingerlike processes in lower edge of the right collar half in the area near the connecting plan with the left half of oral collar (Figure 3f), and showing very little protrusions from lower margin of the acetabulum to the end of the body (Figure 3g). However, the tegument of the dorsal surface showing net-like structures in the hind extremity of the body (Figure 3h), and pit-like structures from some of which short hair-like structures are ejected from the body surface to outside in the area of the oral collar (Figure 3i). These hair-like structures are ranged in number from 1 to 9 in each single pit and measured 0.6-3.7 (2.1) $\times 0.3$ $0.4(0.38) \mu \mathrm{m}$.

\section{DISCUSSION}

The present parasite showed the typical body plan organization of E. heterostomum Rudolphi, 1809 as recorded from previous studies $^{[5,8]}$. This organization includes: (a) the possession of oral collar around the central oral sucker, (b) body constriction at the middle level of acetabulum, (c) outer diverticulation of the intestinal caeca, (d) testes in the posterior half of the body, (e) intertesticular ovary and oötype, (f) pretesticular uterus, and (e) subterminal intercaecal excretory pore. The locality of the present parasite is recorded from Abu Rawash (Giza, Egypt). Genus Euclinostomum (metacercaria or adult) has a wide range of geographical distribution including southern Europe, Russia, India, and various countries in Africa ${ }^{[11]}$. In Egypt, metacercariae of $E$. heterostomum were recovered from body cavity, mesenteries, liver, kidney, and small intestine of Tilapia, Oreochromis, and Clarias species ${ }^{[4,12]}$. In addition, cercaria, metacercaria, and adults of E. ardeolae were also described ${ }^{[7]}$. The present study records the infection in the natural host squacco heron "Ardeola ralloides". However, many authors didn't find the adult forms in the natural state, but obtained them from experimental infection to many piscivorous birds such as
African darter "Anhinga rufa rufa", longtailed shag "Phalacrocorax africanus africanus", grey heron "Ardea cinerea", buff-backed heron "Ardeola ibis ibis", pond heron "Ardeola grayii", and cattle egret "Bubulcus ibis",[2,5,7,8].

Adults of E. ardeolae differ from the present species in having tegument covered by minutes spines, larger body dimensions $(9.32-11.12 \times 3.10-3.70 \mathrm{~mm})$, oral sucker sometimes longer and always less wider $(0.34-0.52 \times 0.40-0.52 \mathrm{~mm})$, larger ventral sucker $(1.73-2.38 \mathrm{~mm})$, shorter and wider anterior testis $(0.58-0.59 \times 1.40-1.73 \mathrm{~mm})$, larger posterior testis $(0.61-1.08 \times 0.12$ $1.23 \mathrm{~mm})$, larger ovary $(0.46-0.51 \mathrm{~mm})$, as well as eggs always longer and sometimes thinner $(0.12-0.14 \times 0.073-0.076 \mathrm{~mm})$. However, number of intestinal diverticula is recorded in E. ardeolae as 10-14 ( \pm 2$)$ in both sides, which doesn't differ greatly from those recorded in the present species ${ }^{[7]}$. Measurements of the body dimensions, as well as anterior testis and posterior testis dimensions of the present species, occur within the range of body, anterior testis, and posterior testis measurements of E. heterostomum Rudolphi, 1809 (4.80$9.82 \times 1.84-3.22 \mathrm{~mm}, 0.54-0.96 \times 0.56-$ $1.38 \mathrm{~mm}$, and $0.42-0.86 \times 0.43-0.90 \mathrm{~mm}$, respectively $)^{[5]}$. In addition, body tegument of $E$. heterostomum is not covered by spines, as recorded in the present parasite ${ }^{[8]}$. Moreover, number of intestinal diverticula of parasite under investigation doesn't vary greatly from those recorded for E. heterostomum ${ }^{[5,8]}$. Ukoli $^{[2]}$ (1966) stated that "the number of diverticula from each caecum has been found to vary considerably within species". However, adults of E. heterostomum differ in having smaller oral sucker $(0.19-0.30 \times 0.22-0.35 \mathrm{~mm})$, slightly larger ventral sucker (0.96-1.31 $\times 0.96-1.34 \mathrm{~mm})$, and longer ovary $(0.32-$ $0.43 \times 0.30-0.41 \mathrm{~mm})$ than those recorded for the present parasite ${ }^{[5]}$.

In the present investigation, the excretory pore is located intercaecal at the posterior end of the body. Similar observations are noticed in metacercaria of E. heterostomum, 
where excretory pore is located dorsally subterminal at the posterior end ${ }^{[2,13]}$. The gonopore of the present species is located within the concavity of the anterior testis; similar observation is noticed in E. $\operatorname{ardeolae}^{[7]}$. Surface topography of the present species is recorded as fingerlike processes and very little protrusions on the ventral surface of the body, while the dorsal surface shows pits and net-like structures. No tegumental spines are noticed in the present study and this in agreement with previously recoded study on E. heterostomum ${ }^{[5]}$. However, body tegument of $E$. ardeolae is spinous $^{[7]}$. In addition, adults' tegument of some members of clinostomatids such as Clinostomum caffarae, $C$. arquus, and $C$. cichlidorum are lacking for spiny structures ${ }^{[14]}$, while metacercarial tegument of many Clinostomum species is spiny ${ }^{[14,15]}$. Moreover, the surface topography of $C$. complanatum demonstrates cobble-stone like protrusions and domeshaped protrusions on ventral surface, and pits and dome-shaped protrusions on dorsal surface ${ }^{[15]}$.

\section{ACKNOWLEDGMENTS}

This research received no specific grant from any funding agency in the public, commercial or not-for-profit sectors. The author has no potential financial conflict of interest.

\section{COMPLIANCE WITH THE ETHICAL STANDARDS}

All procedures contributing to this work comply with the ethical standards of the relevant national guides to the care and use of laboratory animals and have been approved and authorized by the Institutional Animal Care and Use Committee (IACUC) at Faculty of Science, Cairo University, Egypt.

\section{REFERENCES}

[1] Yamaguti, S. (1958). Systema Helminthum (Volume I). The Digenetic Trematodes of Vertebrates (Parts I and II). Interscience Publishers, Inc., New York, USA.

[2] Ukoli, F. M. A. (1966). On Euclinostomum heterostomum (Rudolphi, 1809). J Helminthol, 40: 227-234.

[3] Kanev, I.; Radev, V. and Fried, B. (2002). Family Clinostomidae Lühe, 1901. In: Keys to the Trematoda (Gibson, D. I.; Jones, A. and Bray, R. A. eds), pp. 113-120. CAB International and the Natural History Museum, Wallingford, UK.

[4] Fischthal, J. H. and Kuntz, R. E. (1963). Trematode parasites of fishes from Egypt. Part VI. The metacercaria of Euclinostomum heterostomum (Rudolphi, 1809) Travassos, 1928 (Clinostomidae), with a review of the genus. Transactions of the American Microscopical Society, 82(3): 335-342.

[5] Jhansilakshmibai, K. and Madhavi, R. (1997). Euclinostomum heterostomum (Rudolphi, 1809) (Trematoda): lifecycle, growth and development of the metacercaria and adult. Systematic Parasitology, 38: 51-64.

[6] Zaidi, D. A. and Khan, D. (1975). Life history of Euclinostomum minutus Bhutta and Khan 1975 (Digenea: Euclinostomidae). Pakistan Journal of Zoology, 7: 161-176.

[7] El-Naffar, M. K. and Khalifa, R. M. (1981). Euclinostomum ardeolae sp. nov. (Trematoda: Clinostomatidae). Journal of Egyptian Society of Parasitology, 11: 175-181.

[8] Britz, J.; Saayman, J. E. and van As, J. G. (1984). Anatomy of the metacercaria and adult of Euclinostomum heterostomum (Rudolphi, 1809) (Trematoda: Clinostomatidae). South African Journal of Zoology, 19(2): 91-96.

[9] Goodman, S. M. and Meininger, P. L. (1989). The Birds of Egypt. Oxford University Press, Oxford, UK.

[10] BirdLife International (2011). The Illustrated Encyclopedia of Birds. DK Publishing, London, UK. 
[11] Dönges, J. (1974). The life cycle of Euclinostomum heterostomum (Rudolphi, 1809) (Trematoda: Clinostomatidae). International Journal for Parasitology, 4: 79-90.

[12] Taher, G. A. (2009). Some studies on metacercarial infection in Oreochromis niloticus in Assiut Governorate and their role in transmission of some trematodes to dogs. Ass Univ Bull Environ Res, 12: 63-79.

[13] Suanyuk, N.; Mankhakhet, S.; Soliman, H. et al. (2013). Euclinostomum heterostomum infection in guppies Poecilia reticulata cultured in southern Thailand. Dis Aquat Organ, 104(2): 121-127.

[14] Sereno-Uribe, A.L.; García-Varela, M.; Pinacho-Pinacho, C. D. et al. (2018). Three new species of Clinostomum Leidy, 1856 (Trematoda) from Middle American fish-eating birds. Parasitol Res, 117(7): 2171-2185.

[15] Abidi, S. M. A.; Ahmad, M.; Nizami, W. A. et al. (1988). Clinostomum complanatum: tegumental surface changes during in vivo development. International Journal for Parasitology, 18(4): 433-439.

\section{How to cite this article:}

Mansour, R. M. (2019). First record of Euclinostomum heterostomum from the naturally-infected heron "Ardeola ralloides" in Egypt: a light \& scanning electron microscopy study. Egyptian Journal of Zoology, 72: 22-31 (DOI: 10.12816/ejz.2019.18363.1015). 


\section{التسجيل الأول لطفيلي "Euclinostomum heterostomum" من طائر البلثون

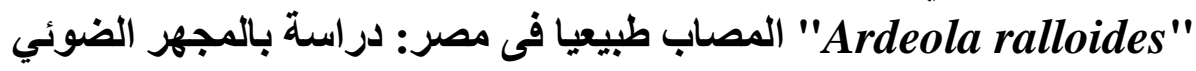

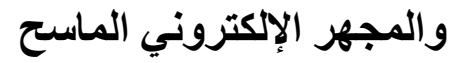

\section{رضا محمد منصور}

قسم علم الحيوان و الحشرات، كلية العلوم، جامعة حلوان، القاهرة، جمهورية مصر العربية

تم فى هذا البحث العثور على أربع عينات بالغة من أحد طفيليات عائلة "Clinostomatidae" من التجويف

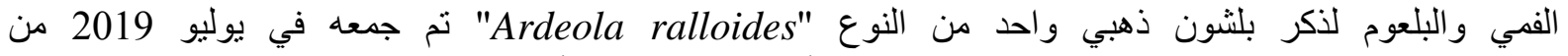

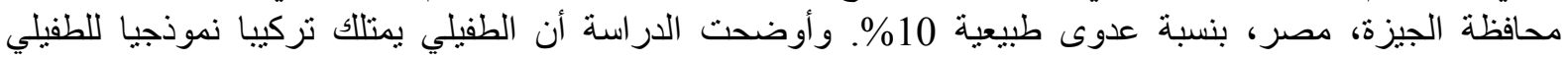

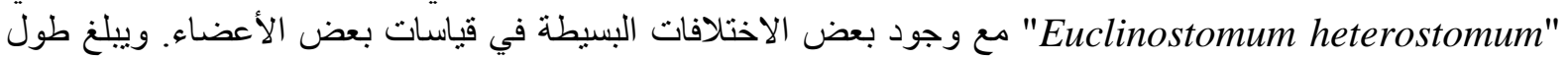

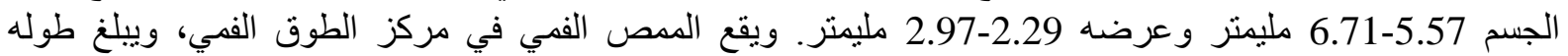

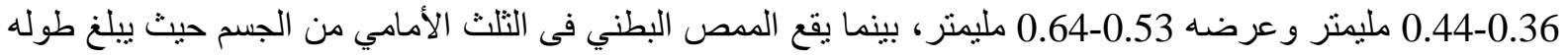

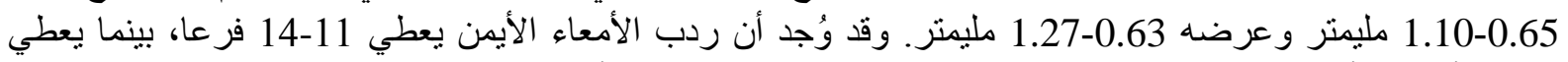

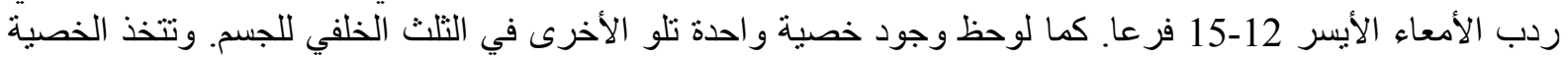

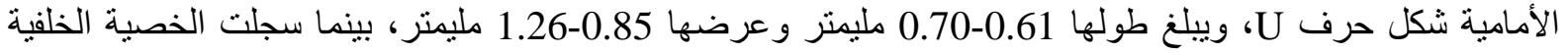

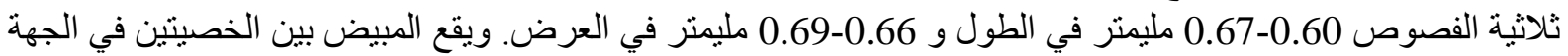

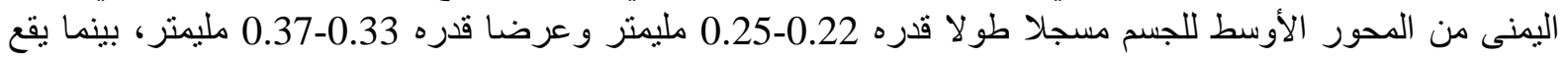

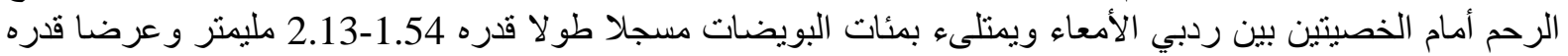

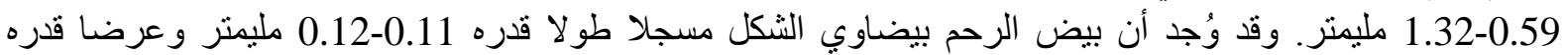

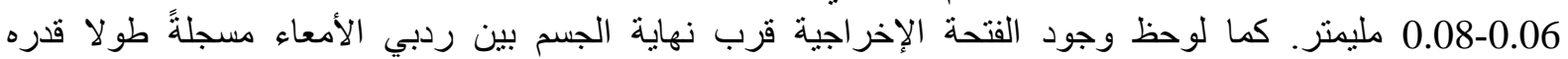

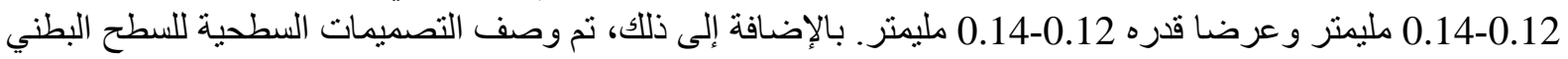
و السطح الظهري للجسم. 